\title{
Thinking Twice about the Evolution of Photosynthesis
}

\author{
Tanai Cardona
}

Department of Life Sciences, Imperial College London, London, UK; t.cardona@imperial.ac.uk

\begin{abstract}
Sam Granick opened his seminal 1957 paper titled Speculations on the Origins and Evolution of Photosynthesis with the assertion that there is a constant urge in human beings to seek beginnings (I concur). This urge has led to an incessant stream of speculative ideas and debates on the evolution of photosynthesis that started in the first half of the twentieth century and shows no signs of abating. Some of these speculative ideas have become commonplace, are taken as fact, but find little support. Here I review and scrutinise three widely accepted ideas that underpin the current study of the evolution of photosynthesis: firstly, that the photochemical reaction centres used in anoxygenic photosynthesis are more primitive than those in oxygenic photosynthesis; secondly, that the probability of acquiring photosynthesis via horizontal gene transfer is greater than the probability of losing photosynthesis; and thirdly, and most importantly, that the origin of anoxygenic photosynthesis predates the origin of oxygenic photosynthesis. I shall attempt to demonstrate that these three ideas are often grounded in incorrect assumptions built on more assumptions with no experimental or observational support. I hope that this brief review will not only serve as a cautionary tale, but also that it will open new avenues of research aimed at disentangling the complex evolution of photosynthesis and its impact on the early history of life and the planet.
\end{abstract}

\section{Keywords}

Photosynthesis, Photosystem, Water oxidation, Oxygenic, Anoxygenic, Reaction centre

\section{The study of the evolution of photosynthesis}

Anoxygenic photosynthesis predates the origin of oxygenic photosynthesis [1]. After the emergence of the earliest forms of anoxygenic phototrophic bacteria, the capacity scattered across a few groups of bacteria via horizontal gene transfer [2,3]. Oxygenic photosynthesis originated in an ancestor of Cyanobacteria when an anoxygenic photosystem gave rise to a water-splitting photosystem [4]. These three basic premises currently underlie the study of the evolution of photosynthesis and would hardly make anyone raise a sceptical eyebrow.

Up for debate are the mechanisms by which Cyanobacteria obtained two distinct photochemical reaction centres linked in series, Photosystem I and Photosystem II, the hallmark of oxygenic photosynthesis. Was the origin of Photosystem I and Photosystem II triggered by a gene duplication event occurring before phototrophy scattered across the tree of life [5-7]? Or were these distinct photosystems acquired via horizontal gene transfer from lineages of anoxygenic phototrophs into a non-photosynthetic ancestor of Cyanobacteria right before the Great Oxidation Event (GOE) $[8,9]$ ? We can therefore debate how long it took for anoxygenic photosynthesis to emerge after the origin of life, and how long it took for oxygenic photosynthesis to emerge after the origin of anoxygenic photosynthesis. We could also debate the identity of the earliest phototrophs, the oldest type of photosystem, and whether this ancestral photosystem used chlorophyll, bacteriochlorophyll, or a mixture of both.

By 2007, when the discovery of phototrophic Acidobacteria was first published [10], all groups of phototrophs then known had been proposed as the innovators of phototrophy, a wide-range of bacterial cell fusion and horizontal gene transfer combinations had been suggested for the birth of Cyanobacteria, and almost every possible scenario for the nature of the earliest photochemical reaction centre had already been put forward. I reviewed this briefly before [11], but see also [12]. It is only proof that the study of the evolution of photosynthesis is fascinating, it exerts an almost irresistible force on the curious mind that 
marvels at the origin of things and drives us to speculate. I have not been able to resist this force despite my best efforts [13]; I have certainly not been the first [14] and will undoubtedly not be the last [15].

This long history of speculation on the evolution of photosynthesis has blurred the line between what is assumed to be true and the facts as supported by rigorous evidence. In this essay I shall demonstrate that several core ideas in the study of the evolution of photosynthesis are based on unsupported-sometimes incorrect - assumptions. A comprehensive critical assessment of the molecular evolution of photosynthesis would require more space than I have here, for that reason I will only focus on these three basic premises: 1) That anoxygenic reaction centres are more "primitive" than those in oxygenic photosynthesis, 2) that the horizontal transfer of photosynthesis is more likely than the loss of photosynthesis, but above all 3) that anoxygenic photosynthesis predates oxygenic photosynthesis.

\section{Primitive photosynthesis}

It is widely believed that the photochemical reaction centres used in anoxygenic photosynthesis are more primitive than those used in oxygenic photosynthesis. Ten years ago, when I was still a PhD student and few years before the study of the evolution of photosynthesis became my full-time job, I came across an interesting and very memorable analogy: that the anoxygenic Type II reaction centre of phototrophic Proteobacteria and Chloroflexi is like a Ford Model T car and in comparison Photosystem II, the wateroxidising enzyme, is like a Formula 1 racing car, implying that the former gave rise to the latter [16]. The logic behind the premise that anoxygenic photosynthesis is primitive goes like this: Water oxidation to oxygen is a difficult chemical reaction that requires great complexity. Photosystem II is more complex than anoxygenic Type II reaction centres; so surely, the anoxygenic reaction centre is more primitive and must have given rise to the oxygenic one.

This assumption is not new and its roots can be traced back to speculative commentary emerging from the early comparative biochemistry of anoxygenic and oxygenic photosynthesis, starting more than 80 years ago [17-19]. For example, H. F. Blum in 1937 reasoned that because oxygenic photosynthesis used four quanta of light to complete a catalytic reaction, unlike anoxygenic photosynthesis, the latter must have been more primitive [19]. Then, this idea was reworked, cemented, and popularised by J. M. Olson [20], whose insight into the evolution of photosynthesis is as influential today as it was back then [21]. It should be noted that this idea became popular well before we had a comprehensive understanding of the photosynthetic processes and long before we had access to sequences or structures of the reaction centres to put it to the test. Now this assumption has taken the appearance of almost undisputable fact.

While at first glance it seems quite reasonable, the flaw is found in the incorrect presupposition that the complexity of oxygenic photosynthesis, and by extension of Photosystem II, evolved before the origin of water oxidation photochemistry. Perhaps it is not too counterintuitive to think that the origin of water oxidation should be considered the trigger that led to an increase in complexity, because the increased complexity exists for the sole purpose of supporting water oxidation. After the origin of water oxidation greater complexity was evolved to make catalysis more robust and efficient [22, 23], to incorporate protection mechanisms against the formation of reactive oxygen species and to diminish the risk of damage $[24,25]$. Increased damage caused by reactive oxygen species led to the evolution of a more complex repair and assembly process [26, 27]. An increase in structural and functional complexity also led to the evolution of more sophisticated regulatory processes acting from picoseconds to weeks and ranging from fine-tuning of electron transfer [28-30] to long-term chromatic adaptation [31]. The bottom line is that an apparent lack of complexity is not a definitive measure of primitiveness, yet that apparent complexity of Photosystem II disappears when the core reaction centre proteins are compared with each other (Figure 1 and 2).

The assumption that anoxygenic reaction centres are more primitive than those used in oxygenic photosystems is not supported by phylogenetic and structural evidence $[11,32]$. Of note is the fact that the heterodimeric core of Photosystem II, made up of D1 and D2, originated from an unambiguous gene duplication event distinct to that which led to the heterodimeric core of the anoxygenic Type II reaction centres, made of L and M [11]. The reason why this is unambiguous lies in the fact that D1 and D2 share much greater sequence and structural identity with each other than with $\mathrm{L}$ and $\mathrm{M}$; and vice versa. While all Type II reaction centre proteins share common ancestry, the known anoxygenic Type II reaction centres are not direct ancestors of Photosystem II. They cannot be described as more primitive and they do not make any better models for what ancestral photosystems looked like than Photosystem II. The assumption that the ancestral Type II reaction centre before L, M, D1, and D2, was more like those found in Proteobacteria 
and Chloroflexi than those in Cyanobacteria, carries a wealth of unproven assumptions: for example, that $\mathrm{L}$ and $\mathrm{M}$ retained more ancestral traits than $\mathrm{D} 1$ and $\mathrm{D} 2$, or that $\mathrm{L}$ and $\mathrm{M}$ are evolving at a significantly slower rate than D1 and D2.

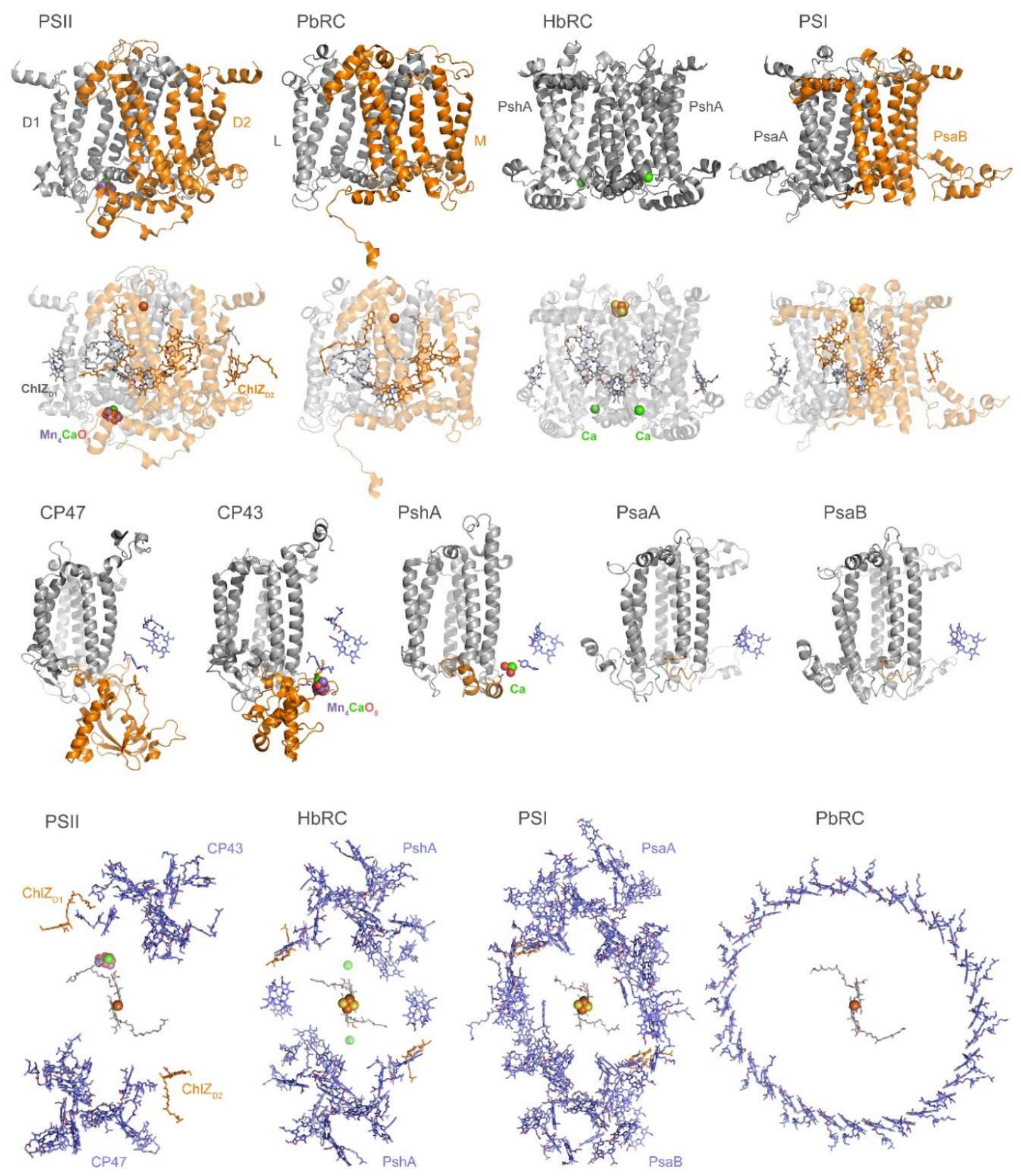

Figure 1. Structural comparisons. Top row, the reaction centre core subunits. PSII stands for cyanobacterial Photosystem II, $\mathrm{PbRC}$ for proteobacterial reaction centre, HbRC for heliobacterial reaction centre, and PSI for cyanobacterial Photosystem I. Second row, the core subunits are shown transparently to highlight the photochemical pigments. Type II reaction centres are characterised by a quinone/non-heme $\mathrm{Fe}^{2+} /$ quinone electron acceptor system. Type I reaction centres are characterised by a $\mathrm{Fe}_{4} \mathrm{~S}_{4}$ cluster electron acceptor system. ChlZ $\mathrm{D}_{\mathrm{D} 1}$ and $\mathrm{ChlZ}_{\mathrm{D} 2}$ are a pair of peripheral chlorophylls bound to the core, but functionally associated with the antenna domain. These are conserved in PSII and other Type I reaction centres and are absent in anoxygenic Type II. Third row, the antenna domains: CP43 and CP47 are the antenna of PSII, PshA of the HbRC, and $\mathrm{PsaA} / \mathrm{PsaB}$ of PSI. In Type I reaction centres the core and the antenna make a single protein. In PSII, the core and the antenna are separate proteins. Anoxygenic Type II reaction centres (PbRC) lack antenna domains, but have independently evolved a new light-harvesting complex. The $\mathrm{Mn}_{4} \mathrm{CaO}_{5}$ cluster is bound by $\mathrm{D} 1$ and $\mathrm{CP} 43$. In the $\mathrm{HbRC}$, a Ca is found at a similar position and it is bound by the core and the antenna as in PSII. Bottom row, a global top view of all the (bacterio)chlorophyll light-harvesting pigments. $\mathrm{Chl}_{\mathrm{D} 1}$ and $\mathrm{ChlZ}_{\mathrm{D} 2}$, and their equivalent in Type I reaction centres, are shown in orange. The other 
antenna pigments are shown in blue. Which of these structures is the most primitive?-PDB ID: PSII, 3wu2; PbRC, 5y5s; HbRC, 5v8k; PSI, 1jb0.

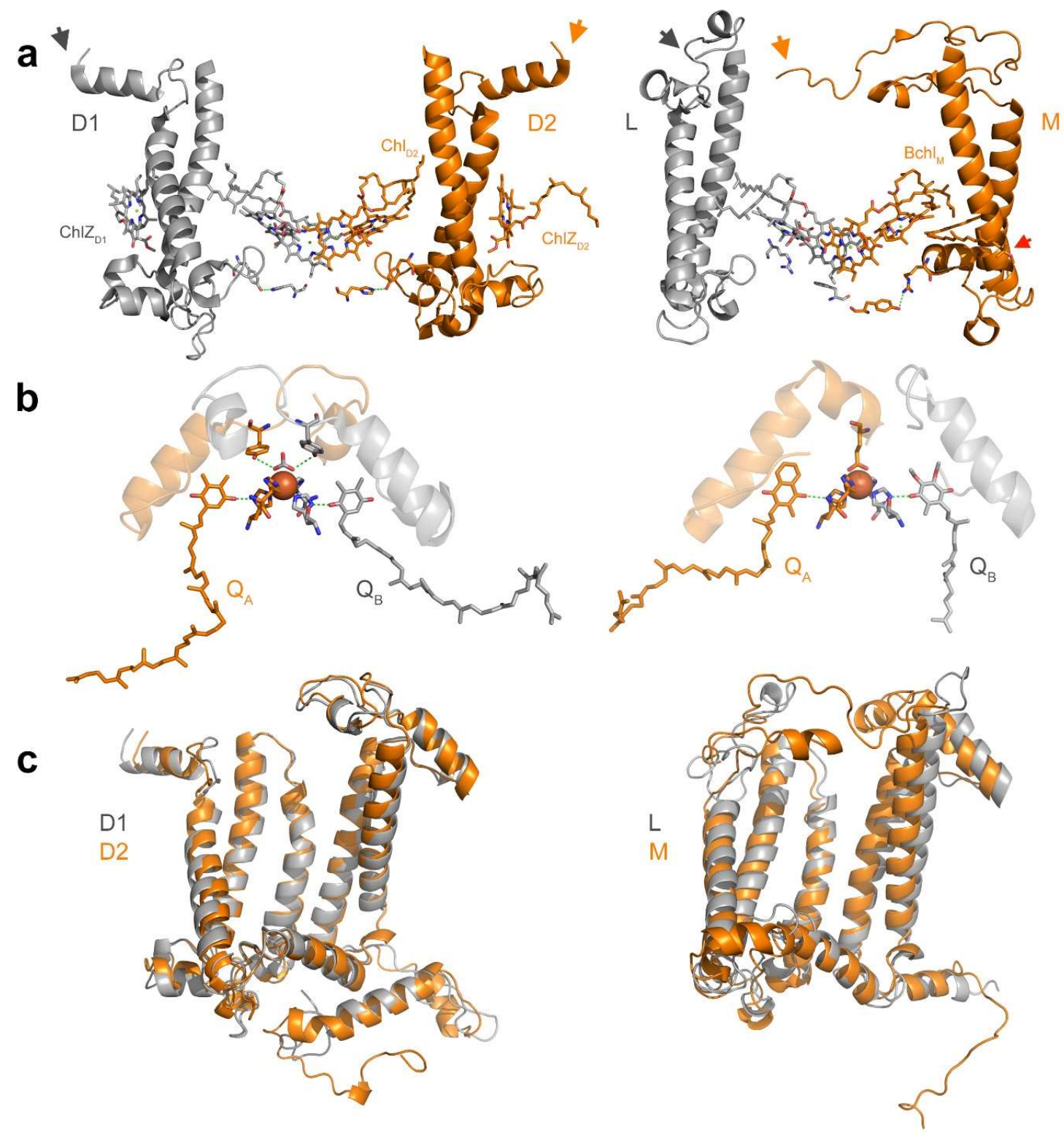

Figure 2. Heterodimerisation of Type II reaction centres. The core of Photosystem II has retained more symmetry than anoxygenic Type II reaction centres. (a) A comparison of some structural elements between Photosystem II and the proteobacterial anoxygenic Type II reaction centre $(\mathrm{PbRC})$. Only the first two transmembrane helices of the core subunits are shown. The N-terminus is marked with a grey and an orange arrow: there is noticeably more symmetry at the N-terminus between D1 and D2 than between L and M. More symmetry in Photosystem II is also observed around the overlap of the $4^{\text {th }}$ transmembrane helix, and the $\mathrm{C}$-terminus. In the $\mathrm{PbRC}$, the bacteriochlorophyll peripheral pigment Bchl $\mathrm{M}_{\mathrm{M}}$ interacts with an asymmetrically located carotenoid. This is not found in the reaction centre of the Chloroflexi, instead a "third" pheophytin takes the position of Bchl $\mathrm{M}_{\mathrm{M}}$ conserving the pigment asymmetry. In Photosystem II, strictly conserved redox active Tyr-His pairs are found on D1 and D2 at the donor side. In the PbRC, an Arg takes the position of Tyr. In M, R164 provides a hydrogen-bond to Y193, which is substituted by Phe in the L subunit. (b) A comparison of symmetry at the quinone/nonheme $\mathrm{Fe}^{2+}$ /quinone electron acceptor system. In Photosystem II, the non-heme $\mathrm{Fe}^{2+}$ is coordinated by bicarbonate, which is symmetrically bound by strictly conserved Tyr residues. In the PbRC, the non-heme $\mathrm{Fe}^{2+}$ is coordinated by a Glu residue in the $\mathrm{M}$ subunit showing that the $\mathrm{PbRC}$ electron acceptor side cannot have retained the ancestral state. (c) Overlap of D1 and D2 (left), and L and M (right). The root-mean-square deviation of atomic positions (RMSD) is a measurement of average distance between overlapped atoms of the backbone's alpha carbons. Between D1 and D2 the RMSD is $2.32 \AA$ over 320 residues, while between $\mathrm{L}$ and $\mathrm{M}$ is $4.37 \AA$ over 232 residues. The greater the symmetry, the better the overlap and the smaller the RMSD over a greater number of residues. 
The case for Type I reaction centres is similar. Anoxygenic Type I reaction centres are homodimeric, while Photosystem I in oxygenic photosynthesis is heterodimeric. Undoubtedly, the homodimeric state is the ancestral state, but that does not necessarily imply that Photosystem I in oxygenic photosynthesis directly originated from the reaction centre of any of the known groups of anoxygenic phototrophs. The phylogeny of Type I reaction centres indicates that all anoxygenic Type I homodimers share a more recent common ancestor to the exclusion of Photosystem I core subunits [11], which is also a reflection of the greater sequence and structural identity among homodimeric Type I reaction centres [33]. It is indeed correct to say that a heterodimeric core is a novel trait relative to the ancestral state, but it would be incorrect to say that PshA or PscA, the reaction centre core subunits of phototrophic Firmicutes, Chlorobi and Acidobacteria, gave rise to the ancestral core subunit of cyanobacterial Photosystem I.

Cardona et al. recently showed that the core subunits of the anoxygenic Type II reaction centres are evolving on average about five times faster than the core subunits of the water-oxidising enzyme [34]. They have likely done so for most of their evolutionary history. That D1 and D2 are evolving significantly slower has two major implications: 1) that the duplication of the oxygenic core that led to D1 and D2 is older than the duplication that led to L and M; and 2) that Photosystem II has retained more ancestral traits than its anoxygenic cousin. This is clearly seen in the structures of the photosystems, as Photosystem II has retained not only greater sequence and structural symmetry at the core, but also greater structural identity with Type I reaction centres (Figure 1 and 2). In a manner similar to Type II reaction centres, by studying the rates of evolution I have also found that the gene duplication leading to the heterodimeric core of cyanobacterial Photosystem I has a pretty good chance of having occurred before the diversification event leading to the different groups of phototrophs with homodimeric Type I reaction centres known today [35].

In conclusion, the assumption that anoxygenic reaction centres are more primitive than those used in oxygenic photosynthesis is, at best, unsupported by their molecular evolution; at worst, incorrect.

\section{Easy transfer}

Arguably there is no topic more controversial in the study of the evolution of photosynthesis than whether the scattered distribution of phototrophy is largely due to widespread horizontal gene transfer or multiple losses across the tree of life. But why is this important? If horizontal transfer of photosynthesis is a relatively easy process, then one could argue that oxygenic photosynthesis could have emerged at a late stage in the evolutionary history of life from the transfer of anoxygenic photosynthesis into a non-photosynthetic ancestor of Cyanobacteria, for example. If, on the other hand, the transfer of photosynthesis is a more difficult process then it may be more likely that the emergence of two distinct photosystems was the result of a gene duplication event, which occurred in a deep but direct ancestor of Cyanobacteria. Certainly, gains and losses of photosynthesis across geological time are not mutually exclusive and there is evidence that both have occurred.

This leads to the next popular assumption in the study of the evolution of photosynthesis: the idea that the probability of a non-photosynthetic organism gaining photosynthesis via horizontal gene transfer is greater than that of a photosynthetic organism losing photosynthesis. Given this assumption, if a clade of photosynthetic bacteria shares a more recent common ancestor with a non-photosynthetic clade, it is assumed that the ancestral state is more likely to be non-photosynthetic [2,3]. The recent discovery of earlybranching non-photosynthetic Cyanobacteria, the Melainabacteria [36] and the Sericytochromatia [9], has lent credence to the hypothesis that oxygenic photosynthesis was invented after horizontal transfer of anoxygenic photosynthesis. This hypothesis relies on the assumption that the ancestral state was nonphotosynthetic.

To the best of my knowledge there are no published studies that have attempted to determine the likelihood of gain $v s$ loss of photosynthesis across the tree of life.

There is only one case of a group of non-photosynthetic bacteria obtaining photosynthesis via horizontal gene transfer. That is the phototrophic Gemmatimonadetes. Zeng et al. demonstrated that this peculiar group of bacteria obtained a photosynthesis gene cluster from a gammaproteobacterium [37]. Any other case of potential gains of photosynthesis in bacteria is ambiguous. The other (more spectacular) case of gain of photosynthesis are the photosynthetic eukaryotes. Horizontal gene transfer occurred from a cyanobacterium endosymbiont into the host nuclear genome of a non-photosynthetic unicellular eukaryote [38, 39]. Nevertheless, after more than a billion years of evolution and the transfer of hundreds, if not thousands [40], 
of cyanobacterial genes into the eukaryotic nuclear genome, the core subunits of the photosystems have remained encoded in the plastid genome.

There are many clear cases of horizontal gene transfer of photosynthesis components between phototorphs. Several studies have shown for example that the marine Synechococcus and Prochlorococcus strains obtained protochlorophyllide reductase from Gammaproteobacteria [5, 41]. Their genes are distinctly and undoubtedly proteobacterial as they cluster specifically within Proteobacteria. Another peculiar case is the transfer of protochlorophyllide and chlorophyllide reductases between a stem-group phototrophic Chlorobi and a stem-group phototrophic Chloroflexi [42], but the direction of transfer is ambiguous.

Recently it was suggested that it was not merely Cyanobacteria which obtained photosynthesis via horizontal gene transfer: a compelling case has been made for phototrophic Chloroflexi evolving via the transfer of photosynthesis as early as $\sim 900$ million years ago [43,44]. Gisriel et al. also proposed that Heliobacteria, the only known phototrophic Firmicutes, also obtained phototrophy via horizontal transfer justified by the presence of a photosynthesis gene cluster [45]. It is noteworthy that Cyanobacteria and Chloroflexi show phylogenetic affinity in many phylogenomic analyses appearing in many instances as each other's closest relatives [46-50]. One has reasons to argue that the most recent common ancestor ( $\mathrm{mrca}$ ) of these two phyla had Type II reaction centres. Indeed, the large phylogenetic distance between the core subunits of the anoxygenic Type II reaction centre and Photosystem II would be consistent with such a scenario. Similar kind of reasoning can be presented against the hypothesis that Heliobacteria obtained phototrophy via horizontal gene transfer. For example, Mix et al. noted that the evolution of Type I reaction centres is consistent with vertical descent [51], and if recent phylogenomic trees of prokaryotes have any resemblance to reality only a single gain of horizontal gene transfer of photosynthesis between phyla of bacteria can be identified [52]: phototrophic Gemmatimonadetes, the exception that proves the rule (Figure 3).

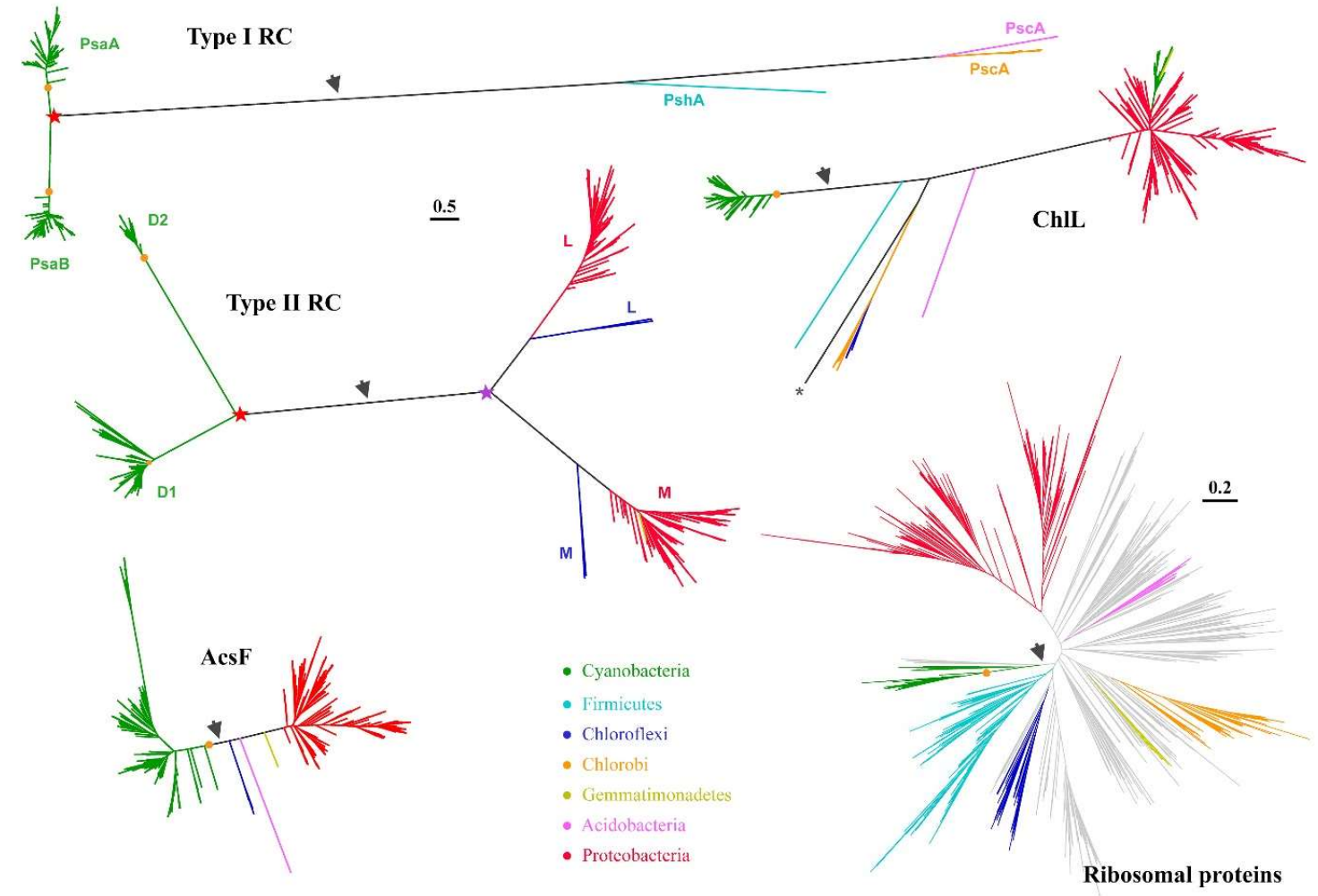

Figure 3. Loss of photosynthesis or horizontal gene transfer? Maximum Likelihood trees of Type I reaction centre proteins, Type II reaction centre proteins, protochlorophyllide reductase subunit L (ChlL), oxygen-dependent Mg-protoporphyrin IX monomethyl ester cyclase (AcsF), and a tree of concatenated ribosomal proteins reported before [52]. The different phototrophic clades are coloured at phylum level. The topology of the trees of photosynthetic components matches closely the tree of ribosomal proteins subtracting non-phototorphic clades and accounting for duplication events (stars). The grey arrow represents the position of the root of the tree as calculated in reference [52]. The orange circle marks the most recent 
common ancestor of Cyanobacteria capable of oxygenic photosynthesis (Oxyphotobacteria). The duplications leading to PsaA and $\mathrm{PsaB}$, and to D1 and D2 are highlighted with a red star, and these duplications must predate the diversification of described Cyanobacteria. Similarly, the duplication leading to L and M (purple star) must predate the origin of phototrophic Chloroflexi and Proteobacteria. The asterisk marks a ChlL subunit from an uncharacterised group of phototrophs. Scale bar represents substitutions per site. All photosynthesis proteins are plotted at the same scale.

An often-cited piece of evidence in favour of horizontal gene transfer scenarios is the fact that in some anoxygenic phototrophs most of the genes required to support phototrophy are encoded in a single gene cluster. Recently, Brinkmann et al. showed that within the family Rhodospirilaceae of Alphaproteobacteria the transfer of complete photosynthesis gene clusters has occurred [53]. The authors calculated that even in the most stringent scenarios at least seven transfer events and eight loss events were needed to reconcile the species tree with the tree of the gene cluster. If these numbers are accurate that would make losses slightly more probable than gains, at least within the Rhodospirilaceae. However, from these seven transfers at least five can be better described as replacements of a native gene cluster with that from a very closely related strain rather than true de novo gains of phototrophy, making the probability of losses substantially greater than gains. It should be noted however, than in none of these transfer cases the photosynthesis gene cluster originated from outside the Rhodospirilaceae. Thus, it could be argued that the greater the phylogenetic distance between the donor and the recipient strain, the less likely it will be that a non-phototroph will successfully integrate and express an entire photosynthesis gene cluster.

We can now wonder if the reason why phototrophic Gemmatimonadetes managed to successfully integrate a photosynthesis gene cluster from Proteobacteria is because the phylum may have been ancestrally phototrophic to begin with, given that Gemmatimonadetes and Chlorobi show strong phylogenetic affinity $[50,52]$. This seems unlikely if one is biased towards thinking that lack of photosynthesis is a more plausible ancestral state. A relevant example of these exchange processes was recently reported in the dinoflagellate Lepidodinium. It was shown that its ancestor lost photosynthesis, discarded the entire pathway for the synthesis of chlorophyll $a$, then regained photosynthesis by acquiring a new algal endosymbiont, and finally rebuilt the chlorophyll synthesis pathway with genes transferred from multiple sources, rather than from the new endosymbiont itself [54].

There are many examples of losses of oxygenic photosynthesis in Cyanobacteria and eukaryotes. One fascinating case is the loss of all Photosystem II-encoding genes in Atelocyanobacterium thalassa (UCYNA), along with the loss of roughly $75 \%$ of the original genome content [55] in only 100 million years [56]. Another interesting case of loss of photosystem genes is that of the cyanobacterium endosymbiont of rhopalodiacean diatoms [57]. In photosynthetic eukaryotes we find the well-known case of parasitic apicomplexa [58], multiple losses in dinoflagellates [59], chrysophytes [60], free-living green algae [61, 62], and holoparasitic angiosperms [63], among probably many others. Within flowering plants, about ten independent losses of photosynthetic capacity have already been documented [64]. One could argue that it is much more likely to lose a single anoxygenic photosynthesis gene cluster than to lose the entire complexity of oxygenic photosynthesis.

Not a single case of horizontal gene transfer of oxygenic photosynthesis between bacteria has been documented. Unlike anoxygenic photosynthesis, the numerous genes now required to support oxygenic photosynthesis are scattered across the cyanobacterial genomes [6] making the probability of a nonphotosynthetic bacterium acquiring oxygenic photosynthesis via horizontal gene transfer nil. In contrast and as we saw in the previous paragraph, the probability of loss of oxygenic photosynthesis is certainly above zero and can occur within less than 100 million years. Therefore, if the probability of loss of photosynthesis is just slightly greater than gain, it is expected that over billions of years the number of lineages of anoxygenic and, in particular, of oxygenic phototrophs, has decreased. This not only explains the scattered distribution of photosynthesis in bacteria, but also the large phylogenetic distance between phototrophic lineages, a distance that is matched by that of their photosynthetic machinery (Figure 3): an aspect that is always overlooked and unaccounted for in horizontal gene transfer scenarios.

This line of thought reveals another assumption on the study of the evolution of photosynthesis not based on any piece of scientific evidence, but nonetheless taken for granted: that Cyanobacteria are the only group of bacteria alive today to have descended from oxygenic phototrophs. In fact, it takes a very simple mental exercise to demonstrate that most of the diversity of oxygenic phototrophs that have existed in the history of the planet likely predates the $m r c a$ of Cyanobacteria. 
All Cyanobacteria share an mrca that was capable of oxygenic photosynthesis [4] in the same way that birds originated from an $m r c a$ that had already evolved feathers $[65,66]$. All Cyanobacteria share an $m r c a$ that had already evolved Photosystem I with a heterodimeric core. This is a trait that has been retained by all oxygenic phototrophs. A heterodimeric Photosystem I is a distinctive and exclusive characteristic of oxygenic photosynthesis and it is widely accepted that the heterodimerisation of the core was an adaptation to oxygenic photosynthesis $[29,67,68]$. PsaA and PsaB, the core subunits of Photosystem I share about $43 \%$ sequence identity: this is true across the entire diversity of oxygenic phototrophs from the earliest branching Cyanobacteria to the most exotic variety of avocado, which implies that the mrca of Cyanobacteria inherited a heterodimeric Photosystem I that had PsaA and PsaB with about $43 \%$ identity. In other words, at the time of the mrca of Cyanobacteria, PsaA and PsaB had already changed by $57 \%$. If we compare the change of sequence identity of PsaA across all oxygenic phototrophs, the maximum level of change is not greater than about $30 \%$, and between all photosynthetic eukaryotes not greater than $20 \%$. It is exactly the same for PsaB. Therefore, most of the sequence change of the core subunits of Photosystem I occurred between the time of the duplication leading to PsaA and PsaB and the mrca of Cyanobacteria [35]. Given that the rates of evolution of complex molecular systems is slow relative to speciation rates [69], that distance between PsaA and PsaB, that amount of change, must have been matched by a substantial biodiversity.

Such a simple exercise exposes the inherent naivety of every proposed evolutionary scenario for the evolution of photosynthesis (including my very own), since it is impossible not to severely underestimate the biodiversity of anoxygenic and oxygenic phototrophic bacteria that have existed through geological time [70]. With all of this in mind and based on the current state of knowledge, the assumption that multiple losses of photosynthesis across the tree of life is less parsimonious than gains via horizontal transfer is far from proven, and might just as well not stand up to scrutiny.

\section{Let there be light}

The chief unproven assumption in the evolution of photosynthesis is that the origin of anoxygenic photosynthesis predates the origin of oxygenic photosynthesis. This assumption can be understood at two fundamental levels: 1) that oxygenic phototrophs evolved from anoxygenic phototrophs or 2) that Photosystem II evolved from an anoxygenic photosystem. The first fundamental level leads to the obvious question of when Cyanobacteria originated, but the question itself is problematic. Only one point in time in the evolution of oxygenic photosynthesis can be clearly defined and accessed through phylogenies of species trees: that is, the $m r c a$ of Cyanobacteria (Figure 4). A broad range of ages for this ancestor have been provided using molecular clocks ranging from 1.5 to 3.5 billion years [8,71-74]. Yet, in the same way that determining when the mrca of birds occurred cannot tell us when or how feathers originated, determining when the mrca of Cyanobacteria occurred cannot tell us when or how photochemical water oxidation to oxygen originated. And, in the same way that having feathers does not make Tyrannosaurus a modern bird, there is a very real possibility that the origin of photochemical water oxidation to oxygen does not necessary fall in a lineage that was the immediate ancestor of the known diversity of Cyanobacteria.

A more precise line of enquiry is to determine for how long water oxidation existed before the mrca of Cyanobacteria. Contrary to what it may appear at a first glance, the answer to this question does not depend on the exact timing of the mrca of Cyanobacteria or whether this ancestor existed before or after the GOE, but instead it is strongly linked to when the earliest stages in the evolution of Photosystem II occurred. For example, the duplication leading to the alpha and beta subunit of ATP synthase is known to have occurred before the last universal common ancestor (LUCA) [75-77]. It follows then that the initial stages in the evolution of ATP synthases is in no way dependent on the time of origin of any particular group of prokaryotes (e.g. Cyanobacteria, Firmicutes, Asgardarchaeota, Euryarchaeota), but it only depends on the molecular events at play during the emergence of the protein complex itself, including the duplication leading to the alpha and beta subunits: an event that predates the divergence of the domains Bacteria and Archaea, and the divergence of F-type and V-type ATP synthases.

This is also the case for oxygenic photosynthesis (Figure 4). The two duplication events, which resulted in the evolution of a heterodimeric Photosystem II, one leading to D1 and D2 and the other to the core antenna subunits, $\mathrm{CP} 43$ and $\mathrm{CP} 47$, are much more likely to have occurred soon after the origin of the earliest reaction centres than right before the $m r c a$ of Cyanobacteria $[34,35]$. These two duplications together with the duplication leading to the heterodimeric core of Photosystem I are, to the best of our knowledge, 
exclusive to oxygenic photosynthesis [78-80]. It was suggested before based on conserved symmetrical structural and functional characteristics of Photosystem II that water oxidation started before the duplication leading to heterodimerisation $[34,79,80]$. Cardona et al. recently calculated that the span of time between the duplication leading to D1 and D2 and the mrca of Cyanobacteria could comfortably be more than a billion years even accounting for the large uncertainties inherent to deep-time molecular clocks (Figure 4) [34]. We also showed that the photosystem existing before the duplication leading to D1 and D2 had already evolved protective mechanisms to prevent the formation of singlet oxygen [34], such as bicarbonatemediated redox tuning of electron transfer at the acceptor side (Figure 2) [24]. Furthermore, our data also indicated that the span of time from the origin of photosynthesis to well past the point of duplication of D1 and D2 could be less than 200 million years. In consequence, the only way to find out how and when oxygenic photosynthesis originated is to resolve what happened during the early evolution of photochemical reaction centres, a time in the history of life that in all likelihood considerably predates the appearance of the taxonomic group that today we recognise on a 16S RNA basis as Cyanobacteria.

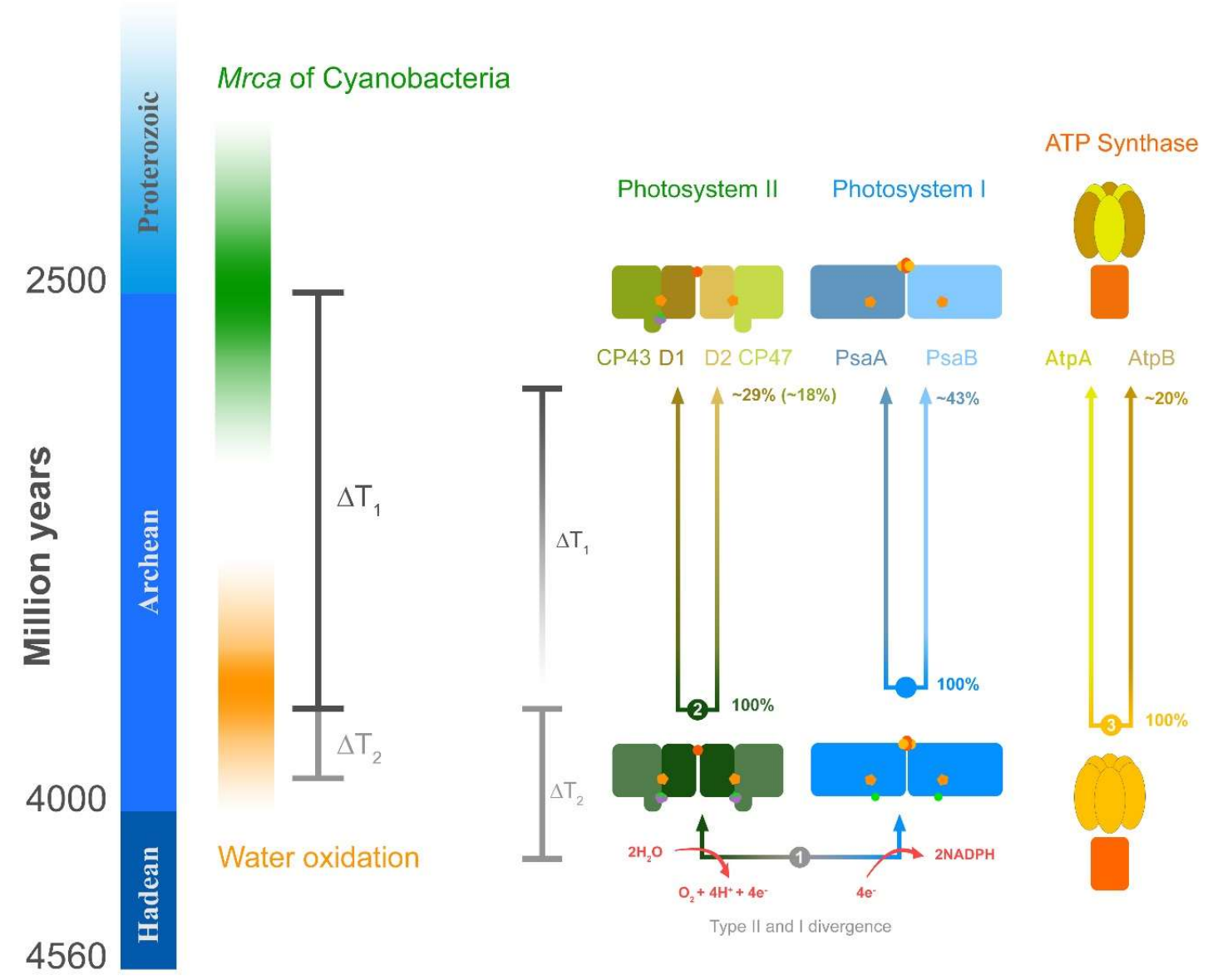

Figure 4. Schematic representation of the evolution of photosynthesis. Two key transitional points are highlighted: the divergence of Type II and Type I reaction centres, marked 1; and the duplication leading to D1 and D2, marked 2. We can then define two periods of time: one starts with the duplication of D1 and D2 and ends with the emergence of standard Photosystem II $\left(\Delta \mathrm{T}_{1}\right)$, which was inherited by the mrca of Cyanobacteria; and the other one starts with the Type II/Type I divergence and ends with the duplication of $\mathrm{D} 1$ and $\mathrm{D} 2\left(\Delta \mathrm{T}_{2}\right)$. Cardona et al. determined that $\Delta \mathrm{T}_{1}$ could comfortably be 1 billion years or more [34]. The main reason for this is the very slow rates of evolution of Photosystem II in Cyanobacteria and photosynthetic eukaryotes. Even when $\Delta \mathrm{T}_{1}$ is 1 billion years the rate of evolution at the moment of duplication is calculated to be about 40 times greater than any rate observed in Cyanobacteria or photosynthetic eukaryotes. It also requires an exponential decrease in the rates approaching current rates before the Archean/Proterozoic transition. Furthermore, due to the exponential decrease in the rates, $\Delta \mathrm{T}_{2}$ can be well under 200 million years. It is worth comparing to the evolution of ATP synthases as both display indistinguishable evolutionary trends, both showing similar rates of evolution and a high degree of sequence conservation across distant taxa. The duplication leading to AtpA and AtpB, marked 3, is known to have occurred in the LUCA. At the moment of duplication, the sequence identity between these two was $100 \%$. Today and across all life (including Cyanobacteria), the level of sequence identity of AtpA and AtpB is about 20\%. It stands to reason that the span of 
time between the AtpA/AtpB duplication and the F-type ATP synthase of the $m r c a$ of Cyanobacteria is in the order of a billion years or more. In fact, an exponential decrease in the rates of evolution of the same magnitude as in Photosystem II is required for that span of time to be as large. In Photosystem II, the level of sequence identity between D1 and D2 is about $29 \%$ and that between $\mathrm{CP} 43$ and $\mathrm{CP} 47$ is about $18 \%$. Now, if $\Delta \mathrm{T}_{1}$ is proposed to be very small, that would require faster rates at the moment of duplication than any rate reported for these types of highly conserved and very slow evolving complexes. If $\Delta \mathrm{T}_{1}$ is 100 million years the rate at the duplication would need to be almost 300 times greater than any observed rate: that is twice as fast as the rate of evolution of short peptide toxins of poisonous animals [134], which are usually less than 20 residues long and are among the fastest evolving proteins in biology. In comparison, the "simplest" reaction centre [45], that of Heliobacteria, has a core protein 608 residues long. This "simplest" of reaction centres is made up of 4 interacting protein subunits, 54 (bacterio)chlorophyll pigments, two carotenoids, a $\mathrm{Fe}_{4} \mathrm{~S}_{4}$ cluster, 4 calcium ions, and a bunch of lipid molecules. Due to the structural complexity of the bioenergetics machinery, including the photosystems and ATP synthase, it is likely that they have maintained relatively slow rates of evolution across their entire evolutionary history.

The second fundamental level of understanding relies on the assumption that anoxygenic reaction centres are more primitive than Photosystem II: as I discussed before, this assumption is incorrect. And all of a sudden, we find ourselves in a situation in which the fundamentals of the evolution of photosynthesis are based on unproven assumptions built on top of unproven assumptions. For instance, the idea that anoxygenic reaction centres are more primitive leads to the presupposition that primordial reaction centres did not have enough oxidising power to split water, which then makes it easy to assume that water oxidation could not be an ancestral trait. An assumption that has not been, in any way, validated. Now these ideas have such a strong grasp on our current understanding of the evolution of life that conceiving a highly oxidising water-splitting photosystem as the primordial photochemical ancestor, and as part of the bioenergetics toolkit of early life, becomes unthinkable [81] despite the absence of unequivocal data supporting otherwise.

From a paleobiological and geochemical perspective, the timing of the origin of oxygenic photosynthesis is far from settled. Rocks older than 2.5 billion years make less than $5 \%$ of the surviving rock mass [82]. Stromatolites, microbial mats and bacteria-like fossils "are present throughout virtually all of the known geological record" [83], but anything older than 2.0 billion years cannot confidently be ascribed to any particular type of phototroph, although they have traditionally been described as "Cyanobacteria-like" [83, 84]. Of note are the 3.22 billion year-old fossilised microbial mats of the Barberton Greenstone Belt in South Africa, which in many ways resemble modern cyanobacterial mats [85]. The record of carbon isotopes fractionation extending to the oldest sedimentary rocks is somewhat inconclusive on the matter as rubisco-derived $\delta^{13} \mathrm{C}$ signatures from anoxygenic and oxygenic phototrophs overlap. Nonetheless and as better said by Nisbet et al. [86]: "In many cases Archaean carbon isotopic results have been taken to demonstrate that the material is the product of an oxygenic biosphere [87, 88]." Furthermore, the interpretation of redox proxies has provided estimates for the origin of oxygenic photosynthesis through the Archean and down to some of the oldest rocks more than 3.7 billion years old [89-100]. Mass-independent fractionation of sulphur isotopes in sedimentary rock has constrained the concentration of oxygen to below $10^{-5}$ of the present atmospheric level (PAL) until about 2.4 billion years ago [101-103]; yet variation in the sulphur isotope record has led researchers to suggest that concentrations of oxygen likely fluctuated greatly across time and space during the Archean [99, 104, 105]. To top it all, the biogenicity, indigenousness, and syngenicity of the earliest rocks and signs of life have been strongly contested [106]. A perfect and recent example of this is the 3.7 billion year-old fossilised stromatolites reported by Nutman et al. [107] followed by a rebuttal [108].

Molecular evolution is equally inconclusive on the timing of the origin of biological oxygen production. For example, reconstructions of the proteome of the LUCA, often pictured as an anaerobe, have retrieved the core subunit of bona fide terminal oxygen reductases [76, 109]; a result that seems to be supported (not without controversy [110]) by phylogenetic analysis of the same enzymes [111,112]. Reconstructions of the LUCA and phylogenetic analysis also appear to indicate an early origin of superoxide dismutase, rubrerythrin, and peroxiredoxin among few other oxygen-using enzymes [76, 109, 113-115]. Oxygentolerant hydrogenases [116] and cytochrome $b_{6} f$ complexes incorporating protective mechanisms against the formation of reactive oxygen species have also been suggested to substantially predate the mrca of Cyanobacteria [117]. To top it all, it was recently suggested based on the physicochemical properties of amino acids that the establishment of the universal genetic code, which should predate the LUCA, required "biospheric molecular oxygen" [118]. And this is not meant to be an exhaustive list. One is then forced to either dismiss the above as artefacts of one sort or another [81, 109]; to accept (rather reluctantly in my 
personal case) that somehow the vanishingly small traces of oxygen expected from abiotic process alone, up to eight orders of magnitude below $10^{-5}$ PAL [119], played any role at all in the early evolution of life $[112,120]$; or alternatively, one must explain away each observation with a series of rationalisations well suited to each particular case.

Efforts to time the evolution of prokaryotes or the emergence of the known groups of phototrophs have also generated puzzling results. For example, the most recent common ancestors of phototrophic Firmicutes [49, 121], of phototrohic Chlorobi [49, 72, 122], of phototrophic Chloroflexi [43, 49, 72], and of phototrophic Proteobacteria $[8,47,49,73]$ have all been timed at about the GOE, but more often than not, after the GOE. What is more, and consistent with the above, my own efforts to understand the evolution of reaction centre proteins as a function of time have suggested that the $\mathrm{L}$ and $\mathrm{M}$ duplication postdate the D1 and D2 duplication; and that the divergence of PshA and PscA postdate the duplication of PsaA and PsaB. Therefore, at the present moment, there is no evidence that clearly demonstrates that anoxygenic photosynthesis ever existed in the absence of oxygenic photosynthesis.

If neither molecular evolution nor the geochemical record have conclusively proven that anoxygenic photosynthesis predates oxygenic photosynthesis, where does the confidence that this is the case come from? I believe this confidence represents an historical and interpretative bias resulting from early speculation on the evolution of photosynthesis, enduring until this day and blurred into the appearance of facts by the inevitable passage of time [14, 17-20, 123-126].

Nevertheless, there is a direct and easy way to demonstrate that the idea that anoxygenic photosynthesis gave rise to oxygenic photosynthesis is based on unproven assumptions. Oxygenic photosynthesis is characterised by the use of a Type II and a Type I reaction centre linked in series. Regardless of whether these two reaction centres got together via an ancient gene duplication or via horizontal gene transfer, all proposed models for the emergence of oxygenic photosynthesis need to fulfil one major requirement. Namely, that at some point in time a transitional photosynthetic stage using an anoxygenic Type II and a Type I reaction centre was favoured over anoxygenic photosynthesis using a single reaction centre. There is no evidence that such a stage in the evolution of anoxygenic photosynthesis ever existed. There are no described anoxygenic phototrophs with genomes encoding both Type I and anoxygenic Type II reaction centre proteins. If towards the evolution of oxygenic photosynthesis such transitional stage proved advantageous over "single-reaction centre" anoxygenic photosynthesis, how is it that "two-reaction centre" anoxygenic photosynthesis has not evolved several times? In theory, it would only require the transfer of a single gene from a bacterium having a homodimeric Type I reaction centre into one having a Type II. That such a type of anoxygenic photosynthesis is not more common than conventional single-reaction centre anoxygenic photosynthesis is paradoxical considering that horizontal gene transfer of photosynthesis is supposed to be a fairly feasible process, that anoxygenic photosynthesis is supposed to have emerged in the early Archean, [127-130], and that most groups of anoxygenic phototrophs have cohabited in microbial mats for billions of years [41, 131]. One could argue that there is a functional barrier preventing the acquisition and integration of a second anoxygenic photosystem.

Frankly, observations from the natural world do not match the expectations derived from current models on the evolution of photosynthesis. Consequently, to prove that anoxygenic indeed predates oxygenic photosynthesis one must first demonstrate that "two-reaction centre" anoxygenic photosynthesis can provide a competitive advantage or increased fitness over "single-reaction centre" anoxygenic photosynthesis. If one can prove that, then one must explain why this two-reaction centre anoxygenic photosynthesis did not outcompete and supersede the only known form of anoxygenic photosynthesis across all photic ecosystems. This has not been done yet.

There is one way out of this paradox: that photochemical water oxidation originated before or at the divergence of Type I and Type II reaction centres.

Three basic observations from the natural world straightforwardly indicate that the origin of reaction centres was intimately linked to the origin of photochemical water oxidation. These are: 1) that oxygenic photosynthesis is the only process that exclusively uses both reaction centres, 2) that anoxygenic photosynthesis using both reaction centres does not exist, and 3) that Photosystem II, the water oxidising enzyme, is a chimeric photosystem made of a Type II core bound to a Type I antenna with both parts needed for the coordination of the $\mathrm{Mn}_{4} \mathrm{CaO}_{5}$ cluster [132]. Given these three observations, a better starting hypothesis in the study of evolution of photosynthesis is that the origin of photochemical reaction centres 
was linked to the origin of water oxidation to oxygen, rather than to the origin of a speculative form of anoxygenic photosynthesis.

There is a fourth observation that had until recently remained unnoticed, yet it is straightforward nonetheless: that Photosystem II is the slowest evolving of all photosystems, evolving at a fifth of the rate of anoxygenic Type II reaction centres [34], and about a third of the rate of Type I reaction centres [35]. That means that Photosystem II is the most likely photosystem to have retained traits once found in the most ancestral reaction centre (Figure 1 and 2). Strong support for this superior starting hypothesis was revealed in the recent structure of the homodimeric Type I reaction centre from Heliobacteria [45]. It showed a calcium bound at the electron donor site of the core with unmistakable structural parallels to the $\mathrm{Mn}_{4} \mathrm{CaO}_{5}$ cluster of Photosystem II (Figure 1) [133]. These structural parallels indicate that the ancestral reaction centre before Type II and Type I had, at the very least, all of the structural elements already in place for the evolution of the $\mathrm{Mn}_{4} \mathrm{CaO}_{5}$ cluster. This is because the most recent common ancestor of Photosystem II and the homodimeric Type I reaction centres is the most recent common ancestor of all reaction centres.

\section{Final words}

The study of the origin and evolution of photosynthesis has fascinated scientists for decades and will continue to capture the imagination of the scientific community and the public for decades to come. It is too soon to claim that we understand how photosynthesis originated, let alone to claim that we understand the photochemistry of the earliest reaction centres to ascertain that the origin of anoxygenic photosynthesis predates the origin of oxygenic photosynthesis. For the field to move forward unhindered more critical, cautious, yet open thought is required. The temptation to speculate will always be too sweet to resist: nonetheless, we should strive to keep the lines between assumptions, hypotheses, predictions and facts well delimited. Only then we can lay new foundations upon which to build a modern framework for the study of the evolution of photosynthesis.

\section{Acknowledgements}

This work was supported by the Leverhulme Trust [grant number RPG-2017-223]. I wish to thank Carmel Cardona for proof-reading the manuscript. I also wish to thank Prof. Anthony W. Larkum and Thomas Oliver for interesting discussions on the topic and additional proof-reading. I am grateful to Prof. A. W. Rutherford and Dr. Andrea Fantuzzi for extensive and stimulating debates. Additional thanks to Prof. Christoph Heubeck and Dr. Martin Homann for useful commentary on the preprint version of this article.

\section{References}

1 Hohmann-Marriott, M. F., Blankenship, R. E. 2011 Evolution of photosynthesis. Annu. Rev. Plant Biol. 62, 515-548. (10.1146/annurev-arplant-042110-103811)

2 Fischer, W. W., Hemp, J., Johnson, J. E. 2016 Evolution of oxygenic photosynthesis. Annu. Rev. Earth Planet. Sci. 44, 647683. (10.1146/annurev-earth-060313-054810)

3 Raymond, J. 2009 The role of horizontal gene transfer in photosynthesis, oxygen production, and oxygen tolerance. Methods Mol. Biol. 532, 323-338. (10.1007/978-1-60327-853-9_19)

4 Cardona, T., Murray, J. W., Rutherford, A. W. 2015 Origin and evolution of water oxidation before the last common ancestor of the Cyanobacteria. Mol. Biol. Evol. 32, 1310-1328. (10.1093/molbev/msv024)

5 Sousa, F. L., Shavit-Grievink, L., Allen, J. F., Martin, W. F. 2013 Chlorophyll biosynthesis gene evolution indicates photosystem gene duplication, not photosystem merger, at the origin of oxygenic photosynthesis. Genome Biol. Evol. 5, 200216. (10.1093/Gbe/Evs127)

6 Mulkidjanian, A. Y., Koonin, E. V., Makarova, K. S., Mekhedov, S. L., Sorokin, A., Wolf, Y. I., Dufresne, A., Partensky, F., Burd, H., Kaznadzey, D., et al. 2006 The cyanobacterial genome core and the origin of photosynthesis. Proc. Natl. Acad. Sci. U.S.A. 103, 13126-13131. (10.1073/pnas.0605709103)

7 Allen, J. F. 2005 A redox switch hypothesis for the origin of two light reactions in photosynthesis. FEBS Lett. 579, $963-$ 968. (10.1016/j.febslet.2005.01.015) 
8 Shih, P. M., Hemp, J., Ward, L. M., Matzke, N. J., Fischer, W. W. 2017 Crown group Oxyphotobacteria postdate the rise of oxygen. Geobiology. 15, 19-29. (10.1111/gbi.12200)

9 Soo, R. M., Hemp, J., Parks, D. H., Fischer, W. W., Hugenholtz, P. 2017 On the origins of oxygenic photosynthesis and aerobic respiration in Cyanobacteria. Science. 355, 1436-1440. (10.1126/science.aal3794)

10 Bryant, D. A., Costas, A. M. G., Maresca, J. A., Chew, A. G. M., Klatt, C. G., Bateson, M. M., Tallon, L. J., Hostetler, J., Nelson, W. C., Heidelberg, J. F., et al. 2007 Candidatus Chloracidobacterium thermophilum: An aerobic phototrophic acidobacterium. Science. 317, 523-526. (10.1126/science.1143236)

11 Cardona, T. 2015 A fresh look at the evolution and diversification of photochemical reaction centers. Photosynth. Res. 126, 111-134. (10.1007/s11120-014-0065-x)

12 Olson, J. M., Blankenship, R. E. 2004 Thinking about the evolution of photosynthesis. Photosynth. Res. 80, 373-386. (10.1023/B:Pres.0000030457.06495.83)

13 Cardona, T. 2016 Reconstructing the origin of oxygenic photosynthesis: Do assembly and photoactivation recapitulate evolution? Front. Plant Sci. 7, 257. (10.3389/fpls.2016.00257)

14 Granick, S. 1957 Speculations on the origins and evolution of photosynthesis. Ann. N. Y. Acad. Sci. 69, $292-308$. $(10.1111 /$ j.1749-6632.1957.tb49665.x)

15 Martin, W. F., Bryant, D. A., Beatty, J. T. 2018 A physiological perspective on the origin and evolution of photosynthesis. FEMS Microbiol. Rev. 42, 205-231. (10.1093/femsre/fux056)

16 Swingley, W. D., Blankenship, R. E., Raymond, J. 2008 Insight into cyanobacterial evolution from comparative genomics. In The cyanobacteria: molecular biology, gnetics and evolution. (ed.^eds. A. Herrero, E. Flores), pp. 24-44. Norfolk: Caister Academic Press.

17 van Niel, C. B. 1949 The comparative biochemistry of photosynthesis. Am. Sci. 37, 371-383.

18 Arnon, D. I., Whatley, F. R., Allen, M. B. 1958 Assimilatory power in photosynthesis: Photosynthetic phosphorylation by isolated chloroplasts is coupled with TPN reduction. Science. 127, 1026-1034. (10.1126/science.127.3305.1026)

19 Blum, H. F. 1937 On the evolution of photosynthesis. The American Naturalist. 71, 350-362 (10.1086/280723)

20 Olson, J. M. 1970 The evolution of photosynthesis. Science. 168, 438-446. (10.1126/science.168.3930.438)

21 Blankenship, R. E., Brune, D. C., Olson, J. C. 2018 Remembering John M. Olson (1929-2017). Photosynth. Res. 137, 161169. (10.1007/s11120-018-0489-9)

22 Vinyard, D. J., Brudvig, G. W. 2017 Progress Toward a Molecular Mechanism of Water Oxidation in Photosystem II. Annu. Rev. Phys. Chem. 68, 101-116. (10.1146/annurev-physchem-052516-044820)

23 Cardona, T., Sedoud, A., Cox, N., Rutherford, A. W. 2012 Charge separation in Photosystem II: A comparative and evolutionary overview. Biochim. Biophys. Acta. 1817, 26-43. (10.1016/j.bbabio.2011.07.012)

24 Brinkert, K., De Causmaecker, S., Krieger-Liszkay, A., Fantuzzi, A., Rutherford, A. W. 2016 Bicarbonate-induced redox tuning in Photosystem II for regulation and protection. Proc. Natl. Acad. Sci. USA. 113, 12144-12149. (10.1073/pnas.1608862113)

25 Cser, K., Vass, I. 2007 Radiative and non-radiative charge recombination pathways in Photosystem II studied by thermoluminescence and chlorophyll fluorescence in the cyanobacterium Synechocystis 6803. Biochim. Biophys. Acta. 1767, 233-243. (10.1016/j.bbabio.2007.01.022)

26 Nickelsen, J., Rengstl, B. 2013 Photosystem II assembly: From cyanobacteria to plants. Annu. Rev. Plant Biol. 64, 609635. (10.1146/annurev-arplant-050312-120124)

27 Nixon, P. J., Michoux, F., Yu, J. F., Boehm, M., Komenda, J. 2010 Recent advances in understanding the assembly and repair of Photosystem II. Ann Bot-London. 106, 1-16. (10.1093/Aob/Mcq059)

28 Sugiura, M., Azami, C., Koyama, K., Rutherford, A. W., Rappaport, F., Boussac, A. 2013 Modification of the pheophytin redox potential in Thermosynechococcus elongatus Photosystem II with PsbA3 as D1. Biochim. Biophys. Acta. 1837, 139148. (10.1016/j.bbabio.2013.09.009) 
29 Rutherford, A. W., Osyczka, A., Rappaport, F. 2012 Back-reactions, short-circuits, leaks and other energy wasteful reactions in biological electron transfer: redox tuning to survive life in $\mathrm{O}_{2}$. FEBS Lett. 586, 603-616. (10.1016/j.febslet.2011.12.039)

30 Nurnberg, D. J., Morton, J., Santabarbara, S., Telfer, A., Joliot, P., Antonaru, L. A., Ruban, A. V., Cardona, T., Krausz, E., Boussac, A., et al. 2018 Photochemistry beyond the red limit in chlorophyll f-containing photosystems. Science. 360, 1210-1213. (10.1126/science.aar8313)

31 Ho, M. Y., Soulier, N. T., Canniffe, D. P., Shen, G. Z., Bryant, D. A. 2017 Light regulation of pigment and photosystem biosynthesis in cyanobacteria. Curr. Opin. Plant Biol. 37, 24-33. (10.1016/j.pbi.2017.03.006)

32 Beanland, T. J. 1990 Evolutionary relationships between Q-Type photosynthetic reaction centers - Hypothesis-testing using parsimony. J. Theor. Biol. 145, 535-545. (10.1016/S0022-5193(05)80487-4)

33 Orf, G. S., Gisriel, C., Redding, K. E. 2018 Evolution of photosynthetic reaction centers: insights from the structure of the heliobacterial reaction center. Photosynth. Res. 10.1007/s11120-018-0503-2, (10.1007/s11120-018-0503-2)

34 Cardona, T., Sanchez-Baracaldo, P., Rutherford, A. W., Larkum, A. W. D. 2019 Early Archean origin of Photosystem II. Geobiology. 17, 127-150. (10.1111/gbi.12322)

35 Cardona, T. 2018 Early Archean origin of heterodimeric Photosystem I. Heliyon. 4, e00548. (10.1016/j.heliyon.2018.e00548)

36 Soo, R. M., Skennerton, C. T., Sekiguchi, Y., Imelfort, M., Paech, S. J., Dennis, P. G., Steen, J. A., Parks, D. H., Tyson, G. W., Hugenholtz, P. 2014 An expanded genomic representation of the phylum Cyanobacteria. Genome Biol. Evol. 6, 10311045. (10.1093/Gbe/Evu073)

37 Zeng, Y. H., Feng, F. Y., Medova, H., Dean, J., Koblizek, M. 2014 Functional Type 2 photosynthetic reaction centers found in the rare bacterial phylum Gemmatimonadetes. Proc. Natl. Acad. Sci. U.S.A. 111, 7795-7800. $(10.1073 /$ pnas.1400295111)

38 Allen, J. F. 2003 The function of genomes in bioenergetic organelles. Philos. Trans. Royal Soc. B. 358, 19-37; discussion 37-18. (10.1098/rstb.2002.1191)

39 Gould, S. B., Waller, R. R., McFadden, G. I. 2008 Plastid evolution. Annu. Rev. Plant Biol. 59, 491-517. (10.1146/annurev.arplant.59.032607.092915)

40 Martin, W., Rujan, T., Richly, E., Hansen, A., Cornelsen, S., Lins, T., Leister, D., Stoebe, B., Hasegawa, M., Penny, D. 2002 Evolutionary analysis of Arabidopsis, cyanobacterial, and chloroplast genomes reveals plastid phylogeny and thousands of cyanobacterial genes in the nucleus. Proc. Natl. Acad. Sci. U.S.A. 99, 12246-12251. (10.1073/pnas.182432999)

41 Bryant, D. A., Liu, Z. F. 2013 Green bacteria: Insights into green bacterial evolution through genomic analyses. In Genome Evolution of Photosynthetic Bacteria. (ed.^eds. J. T. Beatty), pp. 99-150. Amsterdam, The Netherlands: Academic Press.

42 Bryant, D., Liu, Z., LI, T., Zhao, F., Klatt, C. G., Ward, D., Frigaard, N. U., Overmann, J. 2012 Comparative and functional genomics of anoxygenic green bacteria from the taxa Chlorobi, Chloroflexi, and Acidobacteria. In Functional Genomics and Evolution of Photosynthetic Systems. (ed.^eds. R. L. Burnap, W. Vermaas), pp. 47-102. Dordrecht Springer.

43 Shih, P. M., Ward, L. M., Fischer, W. W. 2017 Evolution of the 3-hydroxypropionate bicycle and recent transfer of anoxygenic photosynthesis into the Chloroflexi. Proc. Natl. Acad. Sci. U.S.A. 114, 10749-10754. (10.1073/pnas. 1710798114)

44 Ward, L. M., Hemp, J., Shih, P. M., McGlynn, S. E., Fischer, W. W. 2018 Evolution of phototrophy in the Chloroflexi phylum driven by horizontal gene transfer. Front. Microbiol. 9, 260. (10.3389/fmicb.2018.00260)

45 Gisriel, C., Sarrou, I., Ferlez, B., Golbeck, J. H., Redding, K. E., Fromme, R. 2017 Structure of a symmetric photosynthetic reaction center-photosystem. Science. 357, 1021-1025. (10.1126/science.aan5611)

46 Ciccarelli, F. D., Doerks, T., von Mering, C., Creevey, C. J., Snel, B., Bork, P. 2006 Toward automatic reconstruction of a highly resolved tree of life. Science. 311, 1283-1287. (10.1126/science.1123061)

47 David, L. A., Alm, E. J. 2011 Rapid evolutionary innovation during an Archaean genetic expansion. Nature. 469, 93-96. (10.1038/Nature09649) 
48 Jun, S. R., Sims, G. E., Wu, G. H. A., Kim, S. H. 2010 Whole-proteome phylogeny of prokaryotes by feature frequency profiles: An alignment-free method with optimal feature resolution. Proc. Natl. Acad. Sci. U.S.A. 107, 133-138. (10.1073/pnas.0913033107)

49 Marin, J., Battistuzzi, F. U., Brown, A. C., Hedges, S. B. 2017 The timetree of prokaryotes: New insights into their evolution and speciation. Mol. Biol. Evol. 34, 437-446. (10.1093/molbev/msw245)

50 Segata, N., Bornigen, D., Morgan, X. C., Huttenhower, C. 2013 PhyloPhlAn is a new method for improved phylogenetic and taxonomic placement of microbes. Nat. Commun. 4, (10.1038/Ncomms3304)

51 Mix, L. J., Haig, D., Cavanaugh, C. M. 2005 Phylogenetic analyses of the core antenna domain: Investigating the origin of Photosystem I. J. Mol. Evol. 60, 153-163. (10.1007/s00239-003-0181-2)

52 Hug, L. A., Baker, B. J., Anantharaman, K., Brown, C. T., Probst, A. J., Castelle, C. J., Butterfield, C. N., Hernsdorf, A. W., Amano, Y., Ise, K., et al. 2016 A new view of the tree of life. Nat. Microbiol. 1, 16048. (10.1038/nmicrobiol.2016.48)

53 Brinkmann, H., Goker, M., Koblizek, M., Wagner-Dobler, I., Petersen, J. 2018 Horizontal operon transfer, plasmids, and the evolution of photosynthesis in Rhodobacteraceae. ISME J. 12, 1994-2010. (10.1038/s41396-018-0150-9)

54 Matsuo, E., Inagaki, Y. 2018 Patterns in evolutionary origins of heme, chlorophyll a and isopentenyl diphosphate biosynthetic pathways suggest non-photosynthetic periods prior to plastid replacements in dinoflagellates. PeerJ. 6, e5345. (10.7717/peerj.5345)

55 Thompson, A. W., Foster, R. A., Krupke, A., Carter, B. J., Musat, N., Vaulot, D., Kuypers, M. M. M., Zehr, J. P. 2012 Unicellular cyanobacterium symbiotic with a single-celled eukaryotic alga. Science. 337, 1546-1550. $(10.1126 /$ science.1222700)

56 Cornejo-Castillo, F. M., Cabello, A. M., Salazar, G., Sanchez-Baracaldo, P., Lima-Mendez, G., Hingamp, P., Alberti, A., Sunagawa, S., Bork, P., de Vargas, C., et al. 2016 Cyanobacterial symbionts diverged in the late Cretaceous towards lineagespecific nitrogen fixation factories in single-celled phytoplankton. Nat. Commun. 7, (10.1038/ncomms11071)

57 Nakayama, T., Kamikawa, R., Tanifuji, G., Kashiyama, Y., Ohkouchi, N., Archibald, J. M., Inagaki, Y. 2014 Complete genome of a nonphotosynthetic cyanobacterium in a diatom reveals recent adaptations to an intracellular lifestyle. Proc. Natl. Acad. Sci. U.S.A. 111, 11407-11412. (10.1073/pnas.1405222111)

58 Moore, R. B., Obornik, M., Janouskovec, J., Chrudimsky, T., Vancova, M., Green, D. H., Wright, S. W., Davies, N. W., Bolch, C. J., Heimann, K., et al. 2008 A photosynthetic alveolate closely related to apicomplexan parasites. Nature. 451, 959963. (10.1038/nature06635)

59 Saldarriaga, J. F., Taylor, F. J., Keeling, P. J., Cavalier-Smith, T. 2001 Dinoflagellate nuclear SSU rRNA phylogeny suggests multiple plastid losses and replacements. J. Mol. Evol. 53, 204-213. (10.1007/s002390010210)

60 Grossmann, L., Bock, C., Schweikert, M., Boenigk, J. 2016 Small but manifold - Hidden diversity in "Spumella-like flagellates". J Eukaryot Microbiol. 63, 419-439. (10.1111/jeu.12287)

61 Suzuki, S., Endoh, R., Manabe, R., Ohkuma, M., Hirakawa, Y. 2018 Multiple losses of photosynthesis and convergent reductive genome evolution in the colourless green algae Prototheca. Sci. Rep. 8, (10.1038/s41598-017-18378-8)

62 Smith, D. R., Lee, R. W. 2014 A plastid without a genome: Evidence from the nonphotosynthetic green algal genus Polytomella. Plant Physiol. 164, 1812-1819. (10.1104/pp.113.233718)

63 Ravin, N. V., Gruzdev, E. V., Beletsky, A. V., Mazur, A. M., Prokhortchouk, E. B., Filyushin, M. A., Kochieva, E. Z., Kadnikov, V. V., Mardanov, A. V., Skryabin, K. G. 2016 The loss of photosynthetic pathways in the plastid and nuclear genomes of the non-photosynthetic mycoheterotrophic eudicot Monotropa hypopitys. BMC Plant Biol. 16, 238. $(10.1186 / \mathrm{s} 12870-016-0929-7)$

64 Westwood, J. H., Yoder, J. I., Timko, M. P., dePamphilis, C. W. 2010 The evolution of parasitism in plants. Trends Plant Sci. 15, 227-235. (10.1016/j.tplants.2010.01.004)

65 Sereno, P. C. 1999 The evolution of dinosaurs. Science. 284, 2137-2147. (10.1126/science.284.5423.2137)

66 Xu, X., Zheng, X. T., You, H. L. 2009 A new feather type in a nonavian theropod and the early evolution of feathers. Proc. Natl. Acad. Sci. U.S.A. 106, 832-834. (10.1073/pnas.0810055106) 
67 Ben-Shem, A., Frolow, F., Nelson, N. 2004 Evolution of photosystem I - From symmetry through pseudosymmetry to asymmetry. FEBS Lett. 564, 274-280. (10.1016/S0014-5793(04)00360-6)

68 Hohmann-Marriott, M. F., Blankenship, R. E. 2008 Anoxygenic Type-I photosystems and evolution of photosynthetic reaction centers. In Photosynthetic Protein Complexes. (ed.^eds. P. Fromme), pp. 295-324: Wiley-VCH Verlag GmbH \& Co. KGaA.

69 Shi, T., Bibby, T. S., Jiang, L., Irwin, A. J., Falkowski, P. G. 2005 Protein interactions limit the rate of evolution of photosynthetic genes in cyanobacteria. Mol. Biol. Evol. 22, 2179-2189. (10.1093/molbev/msi216)

70 Louca, S., Shih, P. M., Pennell, M. W., Fischer, W. W., Parfrey, L. W., Doebeli, M. 2018 Bacterial diversification through geological time. Nat. Ecol. Evol. 2, 1458-1467. (10.1038/s41559-018-0625-0)

71 Sanchez-Baracaldo, P., Raven, J. A., Pisani, D., Knoll, A. H. 2017 Early photosynthetic eukaryotes inhabited low-salinity habitats. Proc. Natl. Acad. Sci. USA. 10.1073/pnas.1620089114, (10.1073/pnas.1620089114)

72 Magnabosco, C., Moore, K. R., Wolfe, J. M., Fournier, G. P. 2018 Dating phototropic microbial lineages with reticulate gene histories. Geobiology. 10.1111/gbi.12273, (10.1111/gbi.12273)

73 Betts, H. C., Puttick, M. N., Clark, J. W., Williams, T. A., Donoghue, P. C. J., Pisani, D. 2018 Integrated genomic and fossil evidence illuminates life's early evolution and eukaryote origin. Nat. Ecol. Evol. 2, 1556-1562. (10.1038/s41559-0180644-x)

74 Falcon, L. I., Magallon, S., Castillo, A. 2010 Dating the cyanobacterial ancestor of the chloroplast. ISME J. 4, 777-783. (10.1038/ismej.2010.2)

75 Mulkidjanian, A. Y., Makarova, K. S., Galperin, M. Y., Koonin, E. V. 2007 Inventing the dynamo machine: the evolution of the F-type and V-type ATPases. Nat. Rev. Microbiol. 5, 892-899. (10.1038/nrmicro1767)

76 Ouzounis, C. A., Kunin, V., Darzentas, N., Goldovsky, L. 2006 A minimal estimate for the gene content of the last universal common ancestor: Exobiology from a terrestrial perspective. Res. Microbiol. 157, 57-68. (10.1016/j.resmic.2005.06.015)

77 Gogarten, J. P., Kibak, H., Dittrich, P., Taiz, L., Bowman, E. J., Bowman, B. J., Manolson, M. F., Poole, R. J., Date, T., Oshima, T., et al. 1989 Evolution of the vacuolar $\mathrm{H}^{+}$-ATPase: Implications for the origin of eukaryotes. Proc. Natl. Acad. Sci. U.S.A. 86, 6661-6665. (10.1073/pnas.86.17.6661)

78 Rutherford, A. W., Mattioli, T., Nitschke, W. 1996 The FeS-type photosystems and the evolution of photosynthetic reaction centers. In Origin and evolution of biological energy conversion. (ed.^eds. H. Baltscheffsky), pp. 177-203. New York, N. Y.: VCH.

79 Rutherford, A. W., Nitschke, W. 1996 Photosystem II and the quinone-iron-containing reaction centers. In Origin and evolution of biological energy conversion. (ed.^eds. H. Baltscheffsky), pp. 143-175. New York, N. Y.: VCH.

80 Rutherford, A. W., Faller, P. 2003 Photosystem II: evolutionary perspectives. Philos. Trans. Royal Soc. B. 358, $245-253$. (10.1098/rstb.2002.1186)

81 Martin, W. F., Sousa, F. L. 2015 Early microbial evolution: The age of anaerobes. Cold Spring Harb. Perspect. Biol. 8, a018127. (10.1101/cshperspect.a018127)

82 Veizer, J., Mackenzie, F. T. 2014 Evolution of Sedimentary Rocks. In Treatise on Geochemistry (Second Edition). (ed.^eds. H. D. Holland, K. K. Turekian), pp. 399-435. Oxford: Elsevier.

83 Schopf, J. W. 2011 The paleobiological record of photosynthesis. Photosynth. Res. 107, 87-101. (10.1007/s11120-0109577-1)

84 Schirrmeister, B. E., Sanchez-Baracaldo, P., Wacey, D. 2016 Cyanobacterial evolution during the Precambrian. Int. J. Astrobiol. 15, 187-204. (10.1017/S1473550415000579)

85 Homann, M., Heubeck, C., Airo, A., Tice, M. M. 2015 Morphological adaptations of 3.22 Ga-old tufted microbial mats to Archean coastal habitats (Moodies Group, Barberton Greenstone Belt, South Africa). Precambrian Res. 266, 47-64. (10.1016/j.precamres.2015.04.018)

86 Nisbet, E. G., Grassineau, N. V., Howe, C. J., Abell, P. I., Regelous, M., Nisbet, R. E. R. 2007 The age of Rubisco: the evolution of oxygenic photosynthesis. Geobiology. 5, 311-335. (10.1111/j.1472-4669.2007.00127.x) 
87 Schidlowski, M., Aharon, P. 1992 Carbon cycle and carbon isotope record: Geochemical impact of life over 3.8 Ga of Earth history. In Early Organic Evolution: Implications for Mineral and Energy Resources. (ed.^eds. M. Schidlowski, S. Golubic, M. M. Kimberley, D. M. McKirdy, P. A. Trudinger), pp. 147-175. Berlin, Heidelberg: Springer Berlin Heidelberg.

88 Buick, R. 1992 The antiquity of oxygenic photosynthesis: Evidence from stromatolites in sulfate-deficient Archean lakes. Science. 255, 74-77. (10.1126/science.11536492)

89 Kopp, R. E., Kirschvink, J. L., Hilburn, I. A., Nash, C. Z. 2005 The Paleoproterozoic snowball Earth: a climate disaster triggered by the evolution of oxygenic photosynthesis. Proc. Natl. Acad. Sci. U.S.A. 102, 11131-11136. (10.1073/pnas.0504878102)

90 Holland, H. D. 2006 The oxygenation of the atmosphere and oceans. Philos. Trans. Royal Soc. B. 361, 903-915. $(10.1098 / \mathrm{rstb} .2006 .1838)$

91 Anbar, A. D., Duan, Y., Lyons, T. W., Arnold, G. L., Kendall, B., Creaser, R. A., Kaufman, A. J., Gordon, G. W., Scott, C., Garvin, J., et al. 2007 A whiff of oxygen before the great oxidation event? Science. 317, 1903-1906. (10.1126/science.1140325)

92 Crowe, S. A., Dossing, L. N., Beukes, N. J., Bau, M., Kruger, S. J., Frei, R., Canfield, D. E. 2013 Atmospheric oxygenation three billion years ago. Nature. 501, 535-538. (10.1038/nature12426)

93 Lyons, T. W., Reinhard, C. T., Planavsky, N. J. 2014 The rise of oxygen in Earth's early ocean and atmosphere. Nature. 506, 307-315. (10.1038/nature13068)

94 Planavsky, N. J., Asael, D., Hofmann, A., Reinhard, C. T., Lalonde, S. V., Knudsen, A., Wang, X., Ossa Ossa, F., Pecoits, E., Smith, A. J. B., et al. 2014 Evidence for oxygenic photosynthesis half a billion years before the Great Oxidation Event. Nat. Geosci. 7, 283-286. (10.1038/ngeo2122)

95 Satkoski, A. M., Beukes, N. J., Li, W., Beard, B. L., Johnson, C. M. 2015 A redox-stratified ocean 3.2 billion years ago. Earth Planet. Sci. Lett. 430, 43-53. (10.1016/j.eps1.2015.08.007)

96 Frei, R., Crowe, S. A., Bau, M., Polat, A., Fowle, D. A., Døssing, L. N. 2016 Oxidative elemental cycling under the low $\mathrm{O}_{2}$ Eoarchean atmosphere. Sci. Rep. 6, 21058. (10.1038/srep21058)

97 Rosing, M. T., Frei, R. 2004 U-rich Archaean sea-floor sediments from Greenland - Indications of $>3700$ Ma oxygenic photosynthesis. Earth Planet. Sci. Lett. 217, 237-244. (10.1016/S0012-821x(03)00609-5)

98 Havig, J. R., Hamilton, T. L., Bachan, A., Kump, L. R. 2017 Sulfur and carbon isotopic evidence for metabolic pathway evolution and a four-stepped Earth system progression across the Archean and Paleoproterozoic. Earth-Sci. Rev. 174, 1-21. (10.1016/j.earscirev.2017.06.014)

99 Wang, X. L., Planavsky, N. J., Hofmann, A., Saupe, E. E., De Corte, B. P., Philippot, P., LaLonde, S. V., Jemison, N. E., Zou, H. J., Ossa, F. O., et al. 2018 A Mesoarchean shift in uranium isotope systematics. Geochim. Cosmochim. Acta. 238, 438-452. (10.1016/j.gca.2018.07.024)

100 Kendall, B., Brennecka, G. A., Weyer, S., Anbar, A. D. 2013 Uranium isotope fractionation suggests oxidative uranium mobilization at $2.50 \mathrm{Ga}$. Chem. Geol. 362, 105-114. (10.1016/j.chemgeo.2013.08.010)

101 Farquhar, J., Wing, B. A. 2005 The terrestrial record of stable sulphur isotopes: a review of the implications for evolution of Earth's sulphur cycle. In Mineral Deposits and Earth Evolution. (ed.^eds. I. McDonald, A. J. Boyce, I. B. Butler, R. J. Herrington, D. A. Polya), pp. 167-177. London, UK: Gological Society Special Publication.

102 Zahnle, K., Claire, M., Catling, D. 2006 The loss of mass-independent fractionation in sulfur due to a Palaeoproterozoic collapse of atmospheric methane. Geobiology. 4, 271-283. (10.1111/j.1472-4669.2006.00085.x)

103 Pavlov, A. A., Kasting, J. F. 2002 Mass-independent fractionation of sulfur isotopes in Archean sediments: Strong evidence for an anoxic Archean atmosphere. Astrobiology. 2, 27-41. (10.1089/153110702753621321)

104 Ohmoto, H., Watanabe, Y., Ikemi, H., Poulson, S. R., Taylor, B. E. 2006 Sulphur isotope evidence for an oxic Archaean atmosphere. Nature. 442, 908-911. (10.1038/nature05044)

105 Ono, S., Beukes, N. J., Rumble, D., Fogel, M. L. 2006 Early evolution of atmospheric oxygen from multiple-sulfur and carbon isotope records of the 2.9 Ga Mozaan Group of the Pongola Supergroup, Southern Africa. S. Afr. J. Geol. 109, $97-$ 108. (10.2113/gssajg.109.1-2.97) 
106 Schopf, J. W., Kitajima, K., Spicuzza, M. J., Kudryavtsev, A. B., Valley, J. W. 2018 SIMS analyses of the oldest known assemblage of microfossils document their taxon-correlated carbon isotope compositions. Proc. Natl. Acad. Sci. U.S.A. 115, 53-58. (10.1073/pnas.1718063115)

107 Nutman, A. P., Bennett, V. C., Friend, C. R., Van Kranendonk, M. J., Chivas, A. R. 2016 Rapid emergence of life shown by discovery of 3,700-million-year-old microbial structures. Nature. 537, 535-538. (10.1038/nature19355)

108 Allwood, A. C., Rosing, M. T., Flannery, D. T., Hurowitz, J. A., Heirwegh, C. M. 2018 Reassessing evidence of life in 3,700-million-year-old rocks of Greenland. Nature. 563, 241-244. (10.1038/s41586-018-0610-4)

109 Weiss, M. C., Sousa, F. L., Mrnjavac, N., Neukirchen, S., Roettger, M., Nelson-Sathi, S., Martin, W. F. 2016 The physiology and habitat of the last universal common ancestor. Nat. Microbiol. 1, 16116. (10.1038/nmicrobiol.2016.116)

110 Ducluzeau, A. L., Schoepp-Cothenet, B., van Lis, R., Baymann, F., Russell, M. J., Nitschke, W. 2014 The evolution of respiratory $\mathrm{O}_{2} / \mathrm{NO}$ reductases: an out-of-the-phylogenetic-box perspective. J. Royal Soc. Interface. 11, 20140196. (10.1098/rsif.2014.0196)

111 Brochier-Armanet, C., Talla, E., Gribaldo, S. 2009 The multiple evolutionary histories of dioxygen reductases: Implications for the origin and evolution of aerobic respiration. Mol. Biol. Evol. 26, 285-297. (10.1093/molbev/msn246)

112 Castresana, J., Moreira, D. 1999 Respiratory chains in the last common ancestor of living organisms. J. Mol. Evol. 49, 453-460. (10.1007/P100006568)

113 Knoops, B., Loumaye, E., Van Der Eecken, V. 2007 Evolution of the peroxiredoxins. In Peroxiredoxin Systems. (ed.^eds. L. Flohé, J. R. Harris), pp. 27-40: Springer, Dordrecht.

114 Slesak, I., Slesak, H., Kruk, J. 2012 Oxygen and hydrogen peroxide in the early evolution of life on Earth: In silico comparative analysis of biochemical pathways. Astrobiology. 12, 775-784. (10.1089/ast.2011.0704)

115 Zamocky, M., Janecek, S., Koller, F. 2000 Common phylogeny of catalase-peroxidases and ascorbate peroxidases. Gene. 256, 169-182. (10.1016/S0378-1119(00)00358-9)

116 Pandelia, M. E., Lubitz, W., Nitschke, W. 2012 Evolution and diversification of Group 1 [NiFe] hydrogenases. Is there a phylogenetic marker for $\mathrm{O}_{2}$-tolerance? Biochim. Biophys. Acta. 1817, 1565-1575. (10.1016/j.bbabio.2012.04.012)

117 Nitschke, W., van Lis, R., Schoepp-Cothenet, B., Baymann, F. 2010 The "green" phylogenetic clade of Rieske/cytb complexes. Photosynth. Res. 104, 347-355. (10.1007/s11120-010-9532-1)

118 Granold, M., Hajieva, P., Tosa, M. I., Irimie, F. D., Moosmann, B. 2018 Modern diversification of the amino acid repertoire driven by oxygen. Proc. Natl. Acad. Sci. U.S.A. 115, 41-46. (10.1073/pnas.1717100115)

119 Kasting, J. F., Walker, J. C. G. 1981 Limits on oxygen concentration in the prebiological atmosphere and the rate of abiotic fixation of nitrogen. J. Geophys. Res. (C Oceans). 86, 1147-1158. (10.1029/JC086iC02p01147)

120 Stolper, D. A., Revsbech, N. P., Canfield, D. E. 2010 Aerobic growth at nanomolar oxygen concentrations. Proc. Natl. Acad. Sci. U.S.A. 107, 18755-18760. (10.1073/pnas.1013435107)

121 Moreno-Letelier, A., Olmedo-Alvarez, G., Eguiarte, L. E., Souza, V. 2012 Divergence and phylogeny of Firmicutes from the Cuatro Cienegas Basin, Mexico: a window to an ancient ocean. Astrobiology. 12, 674-684. (10.1089/ast.2011.0685)

122 Brocks, J. J., Love, G. D., Summons, R. E., Knoll, A. H., Logan, G. A., Bowden, S. A. 2005 Biomarker evidence for green and purple sulphur bacteria in a stratified Palaeoproterozoic sea. Nature. 437, 866-870. (10.1038/Nature04068)

123 Copeland, H. F. 1938 The kingdoms of organisms. Q. Rev. Biol. 13, 383-420. (10.1086/394568)

124 Losada, M., Trebst, A. V., Ogata, S., Arnon, D. I. 1960 Equivalence of light and adenosine triphosphate in bacterial photosynthesis. Nature. 186, 753-760. (10.1038/186753a0)

125 Arnon, D. I., Losada, M., Nozaki, M., Tagawa, K. 1961 Photoproduction of hydrogen, photofixation of nitrogen and a unified concept of photosynthesis. Nature. 190, 601-606. (10.1038/190601a0)

126 Olson, J. M. 1981 Evolution of photosynthetic reaction centers. Biosystems. 14, 89-94. (10.1016/0303-2647(81)900241) 
127 Butterfield, N. J. 2015 Proterozoic photosynthesis - a critical review. Palaeontology. 58, 953-972. (10.1111/pala.12211)

128 Nisbet, E. G., Fowler, C. F. R. 2014 The early history of life. In Treatise on Geochemistry. (ed.^eds. K. D. M., W. H. Schlesinger), pp. 1-42. Amsterdam: Elsevier Science.

129 Czaja, A. D., Johnson, C. M., Beard, B. L., Roden, E. E., Li, W. Q., Moorbath, S. 2013 Biological Fe oxidation controlled deposition of banded iron formation in the ca. 3770 Ma Isua Supracrustal Belt (West Greenland). Earth Planet. Sci. Lett. 363, 192-203. (10.1016/j.epsl.2012.12.025)

130 Tice, M. M., Lowe, D. R. 2004 Photosynthetic microbial mats in the 3,416-Myr-old ocean. Nature. 431, 549-552. (10.1038/nature02888)

131 Thiel, V., Tank, M., Bryant, D. A. 2018 Diversity of chlorophototrophic bacteria revealed in the omics era. Annu. Rev. Plant Biol. 69, 21-49. (10.1146/annurev-arplant-042817-040500)

132 Cardona, T. 2017 Photosystem II is a chimera of reaction centers. J. Mol. Evol. 84, 149-151. (10.1007/s00239-017-9784$\mathrm{x})$

133 Cardona, T., Rutherford, A. W. 2019 Evolution of photochemical reaction centres: more twists? BioRxiv. $10.1101 / 502450,(10.1101 / 502450)$

134 Duda, T. F., Jr., Palumbi, S. R. 1999 Molecular genetics of ecological diversification: duplication and rapid evolution of toxin genes of the venomous gastropod Conus. Proc. Natl. Acad. Sci. U.S.A. 96, 6820-6823. (10.1073/pnas.96.12.6820) 